\title{
Dietary inflammatory index and endometrial cancer risk in an Italian case-control study
}

\author{
Nitin Shivappa $^{1,2 *}$, James R. Hébert ${ }^{1,2,3}$, Antonella Zucchetto ${ }^{4}$, Maurizio Montella ${ }^{5}$, Diego Serraino ${ }^{4}$, \\ Carlo La Vecchia ${ }^{6}$ and Marta Rossi ${ }^{6}$ \\ ${ }^{1}$ Cancer Prevention and Control Program, University of South Carolina, Columbia, SC 29208, USA \\ ${ }^{2}$ Department of Epidemiology and Biostatistics, Arnold School of Public Health, University of South Carolina, Columbia, \\ SC 29208, USA \\ ${ }^{3}$ Department of Family and Preventive Medicine, University of South Carolina School of Medicine, Columbia, SC 29208, USA \\ ${ }^{4}$ SOC di Epidemiologia e Biostatistica, Centro di Riferimento Oncologico, Aviano (PN), 33081, Italy \\ ${ }^{5}$ Dipartimento di Epidemiologia, 'Fondazione G. Pascale', Istituto Nazionale Tumori, Naples, 80133, Italy \\ ${ }^{6}$ Department of Clinical Sciences and Community Health, Universitá degli Studi di Milano, Milan, 20133, Italy
}

(Submitted 29 May 2015 - Final revision received 27 August 2015 - Accepted 23 September 2015 - First published online 28 October 2015)

\section{Abstract}

The relation between inflammation deriving from diet and endometrial cancer risk has not yet been investigated. In this study, we explored the association between the dietary inflammatory index (DII) and endometrial cancer risk in an Italian case-control study. Cases comprised 454 patients with incident, histologically confirmed carcinoma of the endometrium, and controls comprised 908 subjects admitted to the same network of hospitals as cases for a wide spectrum of acute, non-neoplastic conditions. DII scores were computed on the basis of dietary intake assessed using a reproducible and valid seventy-eight-item FFQ. OR were calculated through logistic regression models conditioned on age and study centre and adjusted for recognised confounding factors, including total energy intake. Women with the most pro-inflammatory diet

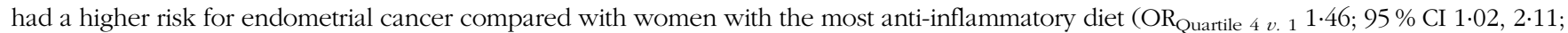
$\left.P_{\text {trend }}=0 \cdot 04\right)$. A pro-inflammatory diet may increase the risk for endometrial cancer.

\section{Key words: Dietary inflammatory index: Diet: Inflammation: Endometrial cancer: Case-control studies: Italy}

Endometrial cancer is the sixth most common form of cancer in women worldwide ${ }^{(1)}$. It is strongly related to unopposed oestrogens, including both those produced endogenously in adipose tissue and those in the form of hormone replacement therapy (HRT). Other risk factors for endometrial cancer are also hormone related and include earlier menarche, nulliparity, overweight/obesity and older age at menopause, whereas oral contraceptive (OC) use is inversely related to endometrial cancer risk ${ }^{(2-4)}$.

Acute inflammation is the body's natural response to insult or injury to tissue, which helps to heal wounds and promote tissue regeneration $^{(5-8)}$, whereas chronic inflammation is a persistent state of low-grade inflammation ${ }^{(8)}$. Various dietary components are known to modulate inflammation ${ }^{(9-11)}$. Chronic inflammation is one of the major risk factors for development of several types of cancer ${ }^{(5,12)}$, and considerable evidence has accumulated on the role of chronic inflammation in endometrial cancer ${ }^{(13-15)}$. This more recent evidence is consistent with findings of Wynder et $a l^{(3)}$ of the relationship between overweight and endometrial cancer from half a century ago. This line of evidence points towards a possible relation between inflammation deriving from dietary exposure and endometrial cancer risk.

A literature-derived, population-based dietary inflammatory index (DII) was developed to assess the inflammatory potential of an individual's diet ${ }^{(16)}$. A typical pro-inflammatory diet is characterised by high consumption of foods rich in SFA, carbohydrate and protein and low consumption of foods rich in PUFA, flavonoids and other selected components and micronutrients. The DII has been validated with various inflammatory markers, including C-reactive protein (CRP) ${ }^{(17,18)}$, IL- $6^{(19,20)}$ and homocysteine ${ }^{(21)}$. The DII has been shown to be associated with possible chronic inflammation-related conditions including intolerance and dyslipidaemia components of the metabolic syndrome in two cross-sectional studies in the USA and Luxembourg $^{(21,22)}$, anthropometric measurements of obesity in the PREDIMED trial in Spain ${ }^{(21)}$, asthma in a case-control study in Australia ${ }^{(23)}$, bone mineral density among postmenopausal women in Iran ${ }^{(24)}$, colorectal cancer in two cancer case-control

Abbreviations: CRP, C-reactive protein; DII, dietary inflammatory index; HRT, hormone replacement therapy; OC, oral contraceptive.

*Corresponding author: Dr N. Shivappa, email shivappa@mailbox.sc.edu 
studies, in Spain ${ }^{(25)}$ and Italy ${ }^{(26)}$, and in three cohort studies in women in the USA ${ }^{(27-29)}$ and pancreatic and prostate cancers in two Italian case-control studies ${ }^{(30,31)}$

This study examined the relation between the DII and endometrial cancer risk in an Italian case-control study ${ }^{(32)}$, in order to test the hypothesis that a pro-inflammatory diet, as indicated by higher DII values, is associated with an increased risk for developing endometrial cancer.

\section{Methods}

The study was conducted between 1992 and 2006 in three Italian areas, including the greater Milan area, the provinces of Udine and Pordenone in northern Italy and the urban area of Naples in southern Italy $^{(32)}$. Cases comprised 454 women (median age, 60 years; range, 18-79 years) with incident, histologically confirmed endometrial cancer (International Classification of Diseases, ninth edition, 182.0), admitted to major teaching and general hospitals of the study areas. Controls comprised 908 women (median age, 61 years; range, 19-80 years) admitted to the same hospital network as cases for a wide spectrum of acute non-neoplastic conditions. Women admitted for gynaecological or hormone-related conditions or for any medical condition related to long-term dietary changes were excluded. Controls were matched with cases by 5 -year age groups and study centre, with a case:control ratio of 1:2. Of controls, $36 \%$ were admitted for traumas, $32 \%$ for other orthopaedic disorders, 9\% for acute surgical conditions and $23 \%$ for other illnesses, including eye, nose, ear or skin disorders. Women with a history of hysterectomy were excluded from the control group. Less than $5 \%$ of both cases and controls approached refused to be interviewed. All study participants signed an informed consent, according to the recommendations of the Institutional Review Boards of each study hospital.

Trained interviewers collected information on sociodemographic characteristics, anthropometric characteristics, lifestyle habits - including tobacco smoking and alcohol drinking - personal medical history and family history of gynaecological cancer, menstrual and reproductive factors, and OC and HRT use during their hospital stay using a structured questionnaire. There were few missing data $(<1 \%$, as seen in Table 1); for these, we imputed values based on the most frequent category according to the subgroup to which they belonged. Subjects' usual diet 2 years before cancer diagnosis or hospital admission (for controls) was assessed using an interviewer-administered FFQ, consisting of seventy-eight items on foods, including the most common Italian recipes, and five items on alcoholic beverages. Subjects were asked to indicate the average weekly frequency of consumption of each dietary item; intakes $<1 /$ week, but at least once a month, were coded as $0 \cdot 5 /$ week. Nutrient and total energy intake was determined using an Italian Food Composition Database. The FFQ showed reproducibility $^{(33,34)}$ and satisfactory validity ${ }^{(35)}$ with Spearman's correlation coefficients between 0.60 and 0.80 for most food items and nutrients.

Dietary information obtained from the FFQ was used to calculate DII $^{(16)}$. Briefly, on the basis of a search of the literature from 1950 to the end of 2010, we identified forty-five food parameters among foods, nutrients and other food components that were associated with six plasma inflammatory markers (IL-1 $\beta$, IL-4, IL-6, IL-10, TNF- $\alpha$ and CRP). We defined a specific DII score for each food parameter on the basis of the literature review and by taking into account the quality and number of published papers (1943 articles were reviewed and scored).

For each study participant, the dietary data were first linked to a global database that was developed on the basis of eleven data sets from around the world and thus provides a robust estimate of the mean and the standard deviation of these forty-five parameters ${ }^{(16)}$. Each subject's exposure relative to the 'standard global mean' was expressed as a $z$-score that was derived by subtracting the 'standard global mean' from the amount reported and then dividing this value by its standard deviation. To minimise the effect of 'right skewing', this value was then converted to a centred percentile score. The subject's DII score was computed by multiplying these values by the specific DII score for each food parameter and then summing together all these forty-five values according to the following formula, $\mathrm{DII}=b_{1} \times n_{1}+b_{2} \times n_{2}+\ldots \ldots \ldots .+b_{45} \times n_{45}$, where $b_{i}$ refers to the literature-derived inflammatory effect score for each of the evaluated food parameter and $n_{i}$ refers to the food parameterspecific centred percentile, which were derived from the dietary data, per each $i$ from 1 to 45 . A higher DII score indicates a more pro-inflammatory diet. The DII computed on this study's FFQ includes data on thirty-one of the forty-five food parameters comprising the DII including carbohydrate, protein, fat, alcohol, fibre, cholesterol, SFA, MUFA, PUFA, $n-3, n-6$, niacin, thiamin, riboflavin, vitamin $\mathrm{B}_{6}, \mathrm{Fe}, \mathrm{Zn}$, vitamin $\mathrm{A}$, vitamin $\mathrm{C}$, vitamin $\mathrm{D}$, vitamin $\mathrm{E}$, folic acid, $\beta$-carotene, anthocyanidins, flavanol, flavonol, flavonones, flavones, isoflavones, caffeine and tea. A flow chart of the DII methodology is shown in Fig. 1. Energy, which is one of the components of DII, was adjusted for in the analyses. The thirteen food parameters missing from this study are onions, garlic, trans-fat, saffron, turmeric, thyme/oregano, ginger, vitamin $\mathrm{B}_{12}$, Se, pepper, rosemary, eugenol and $\mathrm{Mg}$. DII scores were analysed both by quartiles of exposure computed among controls and as a continuous variable of an increment corresponding to approximately $10 \%$ of its range $(5.49$ to -4.67$)$.

OR and the corresponding $95 \%$ CI were estimated using conditional logistic regression models conditioned on study centre and quinquennia of age and adjusted for year of interview, years of education $(<7,7-11, \geq 12$ years, categorically), BMI (categorically, by quartiles), age at menarche (<12, 12-13, $\geq 14$ years, categorically), menopausal status/age at menopause (pre/perimenopause, $<50,50-54, \geq 55$ years, categorically), parity $(0,1,2,3,>3$, categorically), history of diabetes (yes, no), family history of gynaecological cancers, OC use (never, ever) and HRT use (never, ever). Energy adjustment was made using the residual method, including also the term for total energy intake in the model $^{(36)}$. Stratified analyses were carried out according to age $\left(<55,55-69, \geq 70\right.$ years), BMI $\left(<25, \geq 25 \mathrm{~kg} / \mathrm{m}^{2}\right)$, menopausal status (pre/peri and postmenopause), parity ( $0 / \geq 1$ birth), OC use (yes, no) and HRT use (yes, no). To test for heterogeneity across strata, interaction terms were used. Linear tests for trend were performed using the median value within each quartile as an ordinal variable. Statistical tests were performed using SAS ${ }^{\circledR} 9.3$ (SAS Institute Inc.). 
Review of articles published from 1950 to 2010 resulting in 1943 studies linking a total of 45 food parameters with inflammatory biomarkers.
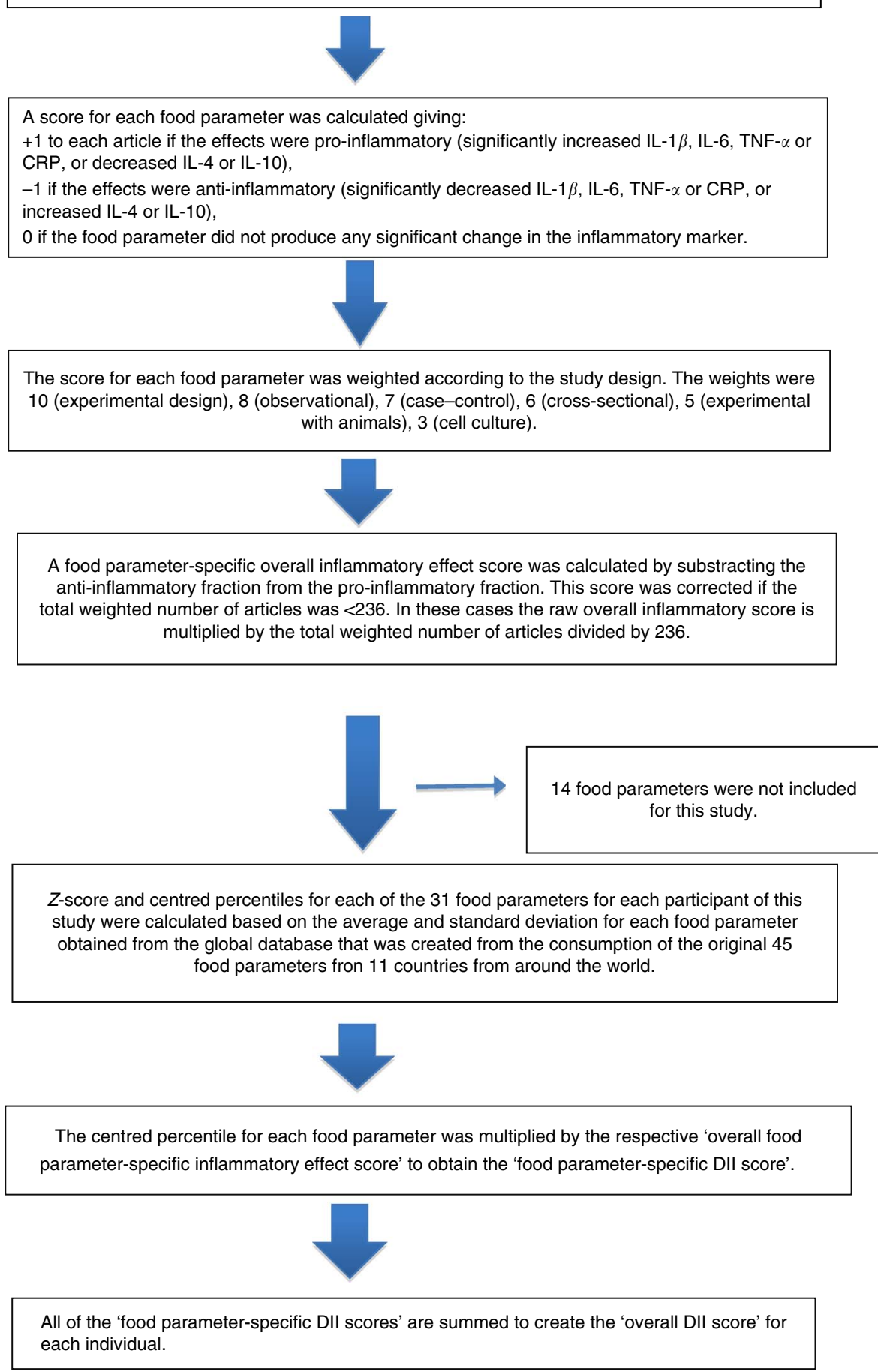

Fig. 1. Sequence of steps in creating the dietary inflammatory index (DII) in the Italian endometrial case-control study. CRP, C-reactive protein.

\section{Results}

The distribution of 454 endometrial cancer cases and 908 controls according to age, education and other selected variables is presented in Table 1. By design, cases and controls had the same age distribution. As compared with controls, cases had a higher BMI and a lower age at menarche, reported more frequently a history of diabetes, and were less frequently OC users, multiparous and more frequently HRT users. Cases and controls were comparable in terms of education and menopausal status.

The mean energy-adjusted DII value for this study was 1.16 (sD 1.45). Cases had a higher mean DII value (0.05 (SD 1.40)) 
Table 1. Distribution of 454 endometrial cancer cases and 908 controls according to selected variables (Italy, 1992-2006) (Number of cases and controls and percentages)

\begin{tabular}{|c|c|c|c|c|c|}
\hline & \multicolumn{2}{|c|}{ Cases } & \multicolumn{2}{|c|}{ Controls } & \multirow[b]{2}{*}{$P$} \\
\hline & $n$ & $\%$ & $n$ & $\%$ & \\
\hline Age (years) & & & & & $<0.0001$ \\
\hline$<55$ & 126 & $27 \cdot 8$ & 252 & $27 \cdot 8$ & \\
\hline $55-69$ & 247 & 54.4 & 494 & 54.4 & \\
\hline$\geq 70$ & 81 & $17 \cdot 8$ & 162 & $17 \cdot 8$ & \\
\hline Education (years) & & & & & 0.57 \\
\hline$<7$ & 263 & 57.9 & 553 & $60 \cdot 9$ & \\
\hline $7-11$ & 119 & $26 \cdot 2$ & 225 & $24 \cdot 8$ & \\
\hline$\geq 12$ & 72 & $15 \cdot 9$ & 130 & $14 \cdot 3$ & \\
\hline $\mathrm{BMI}\left(\mathrm{kg} / \mathrm{m}^{2}\right)$ & & & & & $<0.0001$ \\
\hline$<25$ & 131 & 28.9 & 420 & $46 \cdot 3$ & \\
\hline$\geq 25$ & 323 & $71 \cdot 1$ & 484 & 53.7 & \\
\hline \multicolumn{6}{|l|}{ Age at menarche (years) } \\
\hline$<12$ & 100 & $22 \cdot 0$ & 142 & $15 \cdot 6$ & 0.0002 \\
\hline $12-13$ & 207 & $45 \cdot 6$ & 376 & 41.4 & \\
\hline$\geq 14$ & 145 & $32 \cdot 4$ & 383 & 43.0 & \\
\hline Menopausal status & & & & & 0.81 \\
\hline Pre/perimenopause & 85 & $19 \cdot 2$ & 174 & $19 \cdot 3$ & \\
\hline Postmenopause & 358 & $80 \cdot 8$ & 726 & $80 \cdot 7$ & \\
\hline Parity & & & & & 0.19 \\
\hline 0 & 68 & $15 \cdot 0$ & 126 & 13.9 & \\
\hline 1 & 92 & $20 \cdot 3$ & 150 & $16 \cdot 5$ & \\
\hline$>1$ & 294 & 64.7 & 632 & $69 \cdot 6$ & \\
\hline History of diabetes & & & & & 0.0002 \\
\hline No & 401 & $88 \cdot 3$ & 854 & 94.0 & \\
\hline Yes & 53 & 11.7 & 54 & $6 \cdot 0$ & \\
\hline Oral contraceptive use & & & & & 0.13 \\
\hline Never & 408 & 89.9 & 790 & $87 \cdot 0$ & \\
\hline Ever & 46 & $10 \cdot 1$ & 118 & $13 \cdot 0$ & \\
\hline Hormone replacement therapy & & & & & 0.19 \\
\hline Never & 405 & $89 \cdot 2$ & 830 & $81 \cdot 4$ & \\
\hline Ever & 49 & $10 \cdot 8$ & 78 & $8 \cdot 6$ & \\
\hline Smoking* & & & & & 0.81 \\
\hline Non-smoker & 331 & $72 \cdot 9$ & 646 & $71 \cdot 2$ & \\
\hline Ex-smoker & 48 & $10 \cdot 6$ & 104 & 11.5 & \\
\hline Current smoker & 75 & $16 \cdot 5$ & 157 & $17 \cdot 3$ & \\
\hline
\end{tabular}

* The sum does not add up to the total because of some missing.

compared with controls ( -0.03 (SD 1.48)). Characteristics of control subjects across quartiles of DII are provided in Table 2. There were small, non-significant differences in socio-demographic characteristics, anthropometric measures and hormone-related factors across quartiles of DII

Table 3 shows the distribution of ten food groups across energy-adjusted DII quartiles among controls. Servings of fruit, vegetables and fish decreased significantly across quartiles, whereas servings of pork, sugar and desserts increased significantly.

Table 4 shows the OR of endometrial cancer for the highest $v$. the lowest energy-adjusted DII quartile and adjusted for all selected covariates. Significant positive associations were found: women in the fourth quartile of DII had an increased OR for endometrial cancer compared with women in the lowest quartile $\left(\mathrm{OR}_{\mathrm{Quartile}} 4 v .11\right.$ 1.46; $95 \%$ CI 1.02, 2.11; $\left.P_{\text {trend }}=0.04\right)$. A nearly significant positive association was observed when considering the DII as continuous OR for one unit increment of the DII (corresponding to approximately $10 \%$ of its range) (OR $1.07 ; 95 \%$ CI $0.98,1.17 ; P=0 \cdot 1$ ), suggesting caution of interpretation. When we further adjusted for tobacco smoking and alcohol, the OR did not substantially change.
In Table 5, results are presented according to strata of selected covariates. Apparently, stronger associations were observed between DII and endometrial cancer among postmenopausal women $\left(\mathrm{OR}_{\mathrm{Quartile}} 4 v .1\right.$ 1.57; CI 1.04, 2.38), parous women $\left(\mathrm{OR}_{\mathrm{Quartile}} 4 v .11 \cdot 57\right.$; CI 1.05, 2.34) and non-HRT users (OR Quartile 4 v. 1 1.63; CI 1.10, 2.39). These results should be viewed with caution because of the absence of significant heterogeneity. The $P$ value for heterogeneity was 0.44 for age, 0.34 for BMI, 0.16 for menopausal status, 0.78 for parity and $0 \cdot 70$ for HRT.

\section{Discussion}

The present study, one of the largest case-control investigations on diet and endometrial cancer to date in a southern European population, shows positive associations between DII and endometrial cancer. This result supports the hypothesis that women with a pro-inflammatory diet have a higher risk for developing endometrial cancer.

Previous results from this study indicate foods such as vegetables and coffee as well as various compounds including 
Table 2. Participants' characteristics across energy-adjusted quartiles of dietary inflammatory index (DII) among 908 controls (Italy, 1992-2006) (Numbers and percentages)

\begin{tabular}{|c|c|c|c|c|c|c|c|c|c|}
\hline \multirow[b]{3}{*}{ Characteristics } & \multicolumn{8}{|c|}{ Energy-adjusted DII quartiles } & \multirow[b]{3}{*}{$P^{\star}$} \\
\hline & \multicolumn{2}{|c|}{$<-1.07$} & \multicolumn{2}{|c|}{$-1.07,-0.08$} & \multicolumn{2}{|c|}{$-0.07,1.04$} & \multicolumn{2}{|c|}{$>1.04$} & \\
\hline & $n$ & $\%$ & $n$ & $\%$ & $n$ & $\%$ & $n$ & $\%$ & \\
\hline Age (years) & & & & & & & & & 0.25 \\
\hline$<55$ & 57 & $25 \cdot 1$ & 61 & $26 \cdot 9$ & 69 & $30 \cdot 4$ & 65 & $28 \cdot 6$ & \\
\hline $55-69$ & 137 & 60.4 & 129 & $56 \cdot 8$ & 114 & $50 \cdot 2$ & 114 & $50 \cdot 2$ & \\
\hline$\geq 70$ & 33 & 14.5 & 37 & $16 \cdot 3$ & 44 & 19.4 & 48 & 21.2 & \\
\hline Education (years) & & & & & & & & & 0.96 \\
\hline$<7$ & 134 & $59 \cdot 0$ & 136 & $59 \cdot 9$ & 145 & 63.9 & 138 & $60 \cdot 8$ & \\
\hline $7-11$ & 58 & $25 \cdot 6$ & 58 & $25 \cdot 6$ & 52 & $22 \cdot 9$ & 57 & $25 \cdot 1$ & \\
\hline$>11$ & 35 & $15 \cdot 4$ & 33 & 14.5 & 30 & 13.2 & 32 & $14 \cdot 1$ & \\
\hline BMI $\left(\mathrm{kg} / \mathrm{m}^{2}\right)$ & & & & & & & & & 0.46 \\
\hline$<25$ & 111 & 48.9 & 111 & 48.9 & 100 & 44.1 & 98 & 43.2 & \\
\hline$\geq 25$ & 116 & $51 \cdot 1$ & 116 & $51 \cdot 1$ & 127 & $55 \cdot 9$ & 129 & $56 \cdot 8$ & \\
\hline Age at menarche (years) & & & & & & & & & 0.29 \\
\hline$<12$ & 36 & $15 \cdot 9$ & 37 & $16 \cdot 3$ & 40 & $17 \cdot 6$ & 29 & $12 \cdot 8$ & \\
\hline $12-13$ & 96 & $42 \cdot 3$ & 97 & $42 \cdot 7$ & 99 & 43.6 & 84 & $37 \cdot 0$ & \\
\hline$\geq 14$ & 95 & 41.9 & 93 & 41.0 & 88 & 38.8 & 114 & $50 \cdot 2$ & \\
\hline Menopausal status & & & & & & & & & 0.19 \\
\hline Pre/perimenopause & 36 & $15 \cdot 9$ & 41 & $18 \cdot 1$ & 51 & 22.5 & 51 & 22.5 & \\
\hline Postmenopause & 191 & $84 \cdot 1$ & 186 & 81.9 & 176 & 77.5 & 176 & 77.5 & \\
\hline Parity & & & & & & & & & 0.07 \\
\hline 0 & 34 & $15 \cdot 0$ & 24 & $10 \cdot 6$ & 26 & 11.4 & 42 & 18.5 & \\
\hline 1 & 45 & $19 \cdot 8$ & 34 & $15 \cdot 0$ & 44 & 19.4 & 31 & 13.7 & \\
\hline$>1$ & 148 & $65 \cdot 2$ & 169 & $74 \cdot 4$ & 157 & 69.2 & 154 & $67 \cdot 8$ & \\
\hline History of diabetes & & & & & & & & & 0.31 \\
\hline No & 219 & $96 \cdot 5$ & 212 & 93.4 & 210 & 92.5 & 213 & 93.8 & \\
\hline Yes & 8 & 3.5 & 15 & 6.6 & 17 & 7.5 & 14 & $6 \cdot 2$ & \\
\hline Oral contraceptive use & & & & & & & & & 0.88 \\
\hline No & 195 & $85 \cdot 9$ & 200 & $88 \cdot 1$ & 196 & $86 \cdot 3$ & 199 & $87 \cdot 7$ & \\
\hline Yes & 32 & $14 \cdot 1$ & 27 & 11.9 & 31 & 13.7 & 28 & $12 \cdot 3$ & \\
\hline Hormone replacement therapy & & & & & & & & & 0.36 \\
\hline No & 210 & 92.5 & 203 & $89 \cdot 4$ & 203 & 89.4 & 214 & $94 \cdot 3$ & \\
\hline Yes & 17 & 7.5 & 24 & $10 \cdot 6$ & 24 & $10 \cdot 6$ & 13 & $5 \cdot 7$ & \\
\hline
\end{tabular}

${ }^{*} \chi^{2}$ Test for categorical variables.

Table 3. Distribution of servings of food groups across energy-adjusted quartiles of dietary inflammatory index (DII) among 908 controls (Italy, 1992-2006) (Mean values and standard deviations)

\begin{tabular}{|c|c|c|c|c|c|c|c|c|c|}
\hline \multirow[b]{3}{*}{ Servings/week } & \multicolumn{8}{|c|}{ Energy-adjusted DII quartiles } & \multirow[b]{3}{*}{$P^{\star}$} \\
\hline & \multicolumn{2}{|c|}{$<-1.07$} & \multicolumn{2}{|c|}{$-1.07,-0.08$} & \multicolumn{2}{|c|}{$-0.07,1.04$} & \multicolumn{2}{|c|}{$>1.04$} & \\
\hline & Mean & SD & Mean & SD & Mean & SD & Mean & SD & \\
\hline Fruit & $47 \cdot 4$ & 21.6 & 39.1 & $17 \cdot 3$ & 30.7 & $16 \cdot 9$ & 19.7 & $14 \cdot 4$ & $<0.001$ \\
\hline Vegetables & $21 \cdot 7$ & 7.5 & $19 \cdot 7$ & $6 \cdot 8$ & $16 \cdot 9$ & $6 \cdot 9$ & $12 \cdot 3$ & $7 \cdot 2$ & $<0.001$ \\
\hline Fish & $2 \cdot 0$ & $1 \cdot 2$ & 1.9 & $1 \cdot 2$ & 1.7 & 1.0 & $1 \cdot 6$ & 1.0 & $<0.001$ \\
\hline Egg & 1.5 & $1 \cdot 1$ & 1.6 & $1 \cdot 1$ & 1.6 & 1.3 & $1 \cdot 3$ & 1.4 & 0.06 \\
\hline Coffee & 19.4 & 13.0 & $18 \cdot 5$ & $10 \cdot 8$ & $18 \cdot 6$ & 11.8 & $17 \cdot 3$ & $10 \cdot 9$ & 0.07 \\
\hline Pork & $2 \cdot 1$ & 1.9 & $2 \cdot 6$ & 1.5 & $2 \cdot 8$ & 1.7 & $2 \cdot 8$ & $2 \cdot 4$ & $<0.0001$ \\
\hline Red meat & $3 \cdot 7$ & $2 \cdot 0$ & 4.0 & 1.9 & 4.0 & $2 \cdot 1$ & 3.5 & $2 \cdot 0$ & 0.26 \\
\hline Sugar & $27 \cdot 3$ & 23.4 & $27 \cdot 1$ & 21.4 & $31 \cdot 3$ & $28 \cdot 2$ & 31.8 & $28 \cdot 0$ & 0.02 \\
\hline Cheese & 4.0 & $2 \cdot 3$ & 4.7 & $2 \cdot 6$ & 4.8 & $2 \cdot 8$ & $4 \cdot 4$ & 3.0 & 0.06 \\
\hline Desserts & 4.9 & $4 \cdot 1$ & $5 \cdot 5$ & 4.4 & $6 \cdot 2$ & $6 \cdot 1$ & $6 \cdot 7$ & $7 \cdot 9$ & 0.0004 \\
\hline
\end{tabular}

* This is the $P$ value for the test of trend across DII quartiles.

proanthocyanidins and $\beta$-carotene to be inversely related to endometrial cancer risk ${ }^{(32,37-43)}$. All of these dietary factors contribute to lower DII values ${ }^{(16)}$. Conversely, dietary patterns rich in animal products, starch and SFA, which contribute to higher DII values $^{(16)}$, were positively related to endometrial cancer risk ${ }^{(44)}$. An anti-inflammatory diet - as reflected in lower DII scores - also contains foods that are rich in antioxidant vitamins, flavonoids and fibre. These nutrient-dense, low-energy-content components combine to help keep the BMI low ${ }^{(45)}$. Thus, it may not be possible to disentangle these different aspects.

The positive relationship between DII and endometrial cancer is consistent with a body of evidence from studies 
Table 4. Odds ratios of endometrial cancer for energy-adjusted quartiles of dietary inflammatory index (DII) among 454 cases and 908 controls (Italy, 1992-2006) (Odds ratios and $95 \%$ confidence intervals)

\begin{tabular}{|c|c|c|c|c|c|c|c|c|}
\hline & \multicolumn{7}{|c|}{ Energy-adjusted DII quartiles } & \multirow[b]{3}{*}{$P_{\text {trend }}$} \\
\hline & \multirow{2}{*}{$\frac{<-1.07}{\text { OR }}$} & \multicolumn{2}{|c|}{$-1.07,-0.08$} & \multicolumn{2}{|c|}{$-0.07,1.04$} & \multicolumn{2}{|c|}{$>1.04$} & \\
\hline & & OR & $95 \% \mathrm{Cl}$ & OR & $95 \% \mathrm{Cl}$ & OR & $95 \% \mathrm{Cl}$ & \\
\hline Cases/controls & $92 / 227$ & \multicolumn{2}{|c|}{$120 / 227$} & \multicolumn{2}{|c|}{$121 / 227$} & \multicolumn{2}{|c|}{$121 / 227$} & \\
\hline Model $1^{*}$ & $1 \dagger$ & 1.31 & $0.94,1.82$ & $1 \cdot 31$ & $0.94,1.83$ & $1 \cdot 34$ & $0.96,1.87$ & 0.12 \\
\hline Model 2ł & $1 \dagger$ & 1.34 & $0.94,1.91$ & 1.34 & $0.94,1.92$ & 1.46 & $1 \cdot 02,2 \cdot 11$ & 0.04 \\
\hline
\end{tabular}

Table 5. Odds ratios of endometrial cancer according to energy-adjusted quartiles of dietary inflammatory index (DII) among 454 cases and 908 controls in strata of selected covariates (Italy, 1992-2006)

(Odds ratios and $95 \%$ confidence intervals)

\begin{tabular}{|c|c|c|c|c|c|c|c|c|c|c|}
\hline & \multirow[b]{3}{*}{ Cases/controls } & \multicolumn{8}{|c|}{ Energy-adjusted DII quartiles* } & \multirow[b]{3}{*}{$P_{\text {trend }}$} \\
\hline & & \multicolumn{2}{|c|}{$<-1.07$} & \multicolumn{2}{|c|}{$-1.07,-0.08$} & \multicolumn{2}{|c|}{$-0.07,1.04$} & \multicolumn{2}{|c|}{$>1.04$} & \\
\hline & & OR & $95 \% \mathrm{Cl}$ & OR & $95 \% \mathrm{Cl}$ & OR & $95 \% \mathrm{Cl}$ & OR & $95 \% \mathrm{Cl}$ & \\
\hline \multicolumn{11}{|l|}{ Age (years) } \\
\hline$<55$ & $126 / 252$ & & $1 \dagger$ & 1.09 & $0.54,2.22$ & $1 \cdot 10$ & $0.55,2.23$ & 1.31 & $0.65,2.66$ & 0.44 \\
\hline $55-69$ & $247 / 494$ & & $1 \dagger$ & 1.21 & $0.75,1.97$ & 1.42 & $0.86,2.35$ & 1.55 & $0.93,2.59$ & 0.08 \\
\hline$\geq 70$ & $81 / 162$ & & $1 \dagger$ & 2.54 & $0.89,7.25$ & 1.68 & $0.60,4.66$ & $2 \cdot 27$ & $0.81,6.41$ & 0.27 \\
\hline \multicolumn{11}{|l|}{$\mathrm{BMI}\left(\mathrm{kg} / \mathrm{m}^{2}\right)$} \\
\hline$<25$ & $131 / 420$ & & $1 \dagger$ & $1 \cdot 23$ & $0 \cdot 67,2 \cdot 24$ & 1.69 & $0.94,2.05$ & $1 \cdot 16$ & $0 \cdot 62,2 \cdot 17$ & 0.47 \\
\hline$\geq 25$ & $323 / 486$ & & $1 \dagger$ & 1.41 & $0.90,2 \cdot 21$ & 1.20 & $0.76,1.89$ & 1.56 & $0.99,2.46$ & 0.11 \\
\hline \multicolumn{11}{|l|}{ Menopausal status } \\
\hline Pre/perimenopause & $87 / 179$ & & $1 \dagger$ & 0.97 & $0.40,2.35$ & 0.72 & $0.31,1.67$ & 0.74 & $0.31,1.76$ & 0.39 \\
\hline Postmenopause & $367 / 727$ & & $1 \dagger$ & 1.38 & $0.93,2.06$ & 1.46 & $0.97,2.19$ & 1.57 & $1 \cdot 04,2 \cdot 38$ & 0.04 \\
\hline \multicolumn{11}{|l|}{ Parity } \\
\hline 0 & $68 / 126$ & & $1 \dagger$ & 1.76 & $0.65,4.75$ & 1.85 & $0.67,5.08$ & 0.85 & $0.31,2 \cdot 31$ & 0.68 \\
\hline$\geq 1$ & $386 / 782$ & & $1 \dagger$ & 1.22 & $0.83,1.80$ & 1.25 & $0.84,1.85$ & 1.57 & $1.05,2.34$ & 0.03 \\
\hline \multicolumn{11}{|l|}{ HRT use } \\
\hline Yes & $49 / 78$ & & $1 \dagger$ & 0.63 & $0.16,2.39$ & 0.28 & $0.06,1.23$ & 0.55 & $0.12,2.64$ & 0.21 \\
\hline No & $405 / 830$ & & $1 \dagger$ & 1.43 & $0.98,2 \cdot 10$ & 1.51 & $1.03,2.22$ & 1.62 & $1 \cdot 10,2.39$ & 0.02 \\
\hline
\end{tabular}

HRT, hormone replacement therapy.

* Estimated from multiple logistic regression models, conditioned on study centre and quinquennia of age, and adjusted for year of interview, education, BMI, age at menarche, menopausal status and age at menopause, parity, history of diabetes, family history of gynaecological cancers, oral contraceptive use, HRT use and total energy intake. † Reference category.

examining the effect of various dietary components on endometrial cancer. These include observational studies indicating a modest positive association between high glycaemic load, but not glycaemic index, and endometrial cancer ${ }^{(46,47)}$. A metaanalysis of case-control studies suggests that meat consumption, particularly red meat, increases endometrial cancer risk, whereas poultry, fish and eggs produce inconsistent associations ${ }^{(48)}$. A protective role was observed for coffee consumption in endometrial cancer risk in the NIH-AARP (National Institutes for Health-American Association of Retired Persons) study ${ }^{(49)}$ and in the PLCO (Prostate, Lung, Colorectal and Ovarian Colorectal Cancer Screening Trial) cohort ${ }^{(50)}$. A systematic review showed inverse associations between non-preserved vegetable intake and endometrial cancer, but a direct association with preserved vegetable intake ${ }^{(51)}$. The latest report from World Cancer Research Foundation on diet and endometrial cancer indicated a probable protective role of coffee and increased risk from glycaemic load ${ }^{(52)}$. Additionally, in a simulated study, macrobiotic and Mediterranean meal plans exhibited antiinflammatory potential, based on the derived DII scores, whereas a fast food diet had a pro-inflammatory score ${ }^{(53)}$.

Previous studies have shown inflammation to be associated with endometrial cancer. Results from the Women's Health Initiative showed that CRP was positively associated with endometrial cancer $^{(54)}$. In a Canadian case-control study, endometrial cancer cases had consistently higher mean levels of TNF- $\alpha$, IL- 6 and CRP compared with controls in predominantly postmenopausal women ${ }^{(15)}$. In a case-control study, nested within the European Prospective Investigation into Cancer and Nutrition, higher levels of pro-inflammatory cytokines (CRP, IL-6 and IL-1Ra) were associated with increased risk for endometrial cancer ${ }^{(14)}$.

One of the possible mechanisms responsible for the observed positive association between the DII and endometrial cancer could be through the effect of pro-inflammatory diet on insulin resistance via increasing systemic inflammation ${ }^{(55,56)}$. 
Consumption of foods such as meat and butter have been shown to increase systemic inflammation by increasing levels of high-sensitivity CRP, E-selection and soluble vascular cell adhesion molecule- ${ }^{(55)}$, which then are responsible for increasing insulin resistance ${ }^{56,57)}$. Increasing insulin resistance then leads to increased circulating levels of insulin that has been demonstrated to play a role in the development of endometrial cancer by inhibiting apoptosis and stimulating cell proliferation $^{(13)}$ and by influencing the insulin-like growth factor axis, resulting in alterations in sex hormone metabolism ${ }^{(57)}$. The association was apparently stronger in postmenopausal women, as for several reproductive and hormonal correlates of endometrial cancer ${ }^{(58)}$. These results indicate a possible aetiological role of diet-associated inflammation, as indicated by the DII, in the development of endometrial cancer in scenarios where hormonal exposures are generally low.

With reference to possible sources of bias, dietary habits of hospital controls may differ from those of the general population ${ }^{(59)}$. In this study, however, we excluded from the control group all diagnoses that might have involved any obvious connection to dietary intake or to health-related changes in diet. With reference to information bias, cases and controls were interviewed in similar settings, and data provided by hospital controls have shown satisfactory reproducibility ${ }^{(60)}$. The nearly complete participation of cases and controls and the inclusion of acute conditions unrelated to diet in the comparison group militate against a major role of selection bias. Furthermore, awareness of dietary hypotheses in endometrial cancer aetiology was unlikely in this Italian population. Another limitation is the non-availability of the remaining thirteen food parameters for the DII calculation. DII scores calculated from these thirty-one food parameters have not been validated with inflammatory markers. However, in previous validation studies, DII scores have been calculated from food parameters ranging from seventeen to forty-four ${ }^{(17,19)}$. Moreover, there could be a possible overestimation due to the inclusion of food items in the DII calculation that are also a source of nutrients. It also should be noted, however, that each of these food items has an inflammatory effect score, which is derived from an extensive review of the literature looking at the association between these foods and inflammation. Among the strengths of our study were the large data set, the similar catchment areas across cases and controls and the satisfactory validity of information collected on dietary habits ${ }^{(33,35)}$. Also, the DII score, which takes into account both pro- and anti-inflammatory food parameters that characterise virtually all human diets, more accurately reflects the relationship of the inflammatory potential of diet to affect cancer risk than would nutrients considered individually.

In conclusion, this unique, large study on endometrial cancer and DII indicates a possible role of diet in endometrial cancer risk through the process of inflammation. Confirmatory results from other studies are required to establish this association.

\section{Acknowledgements}

This study was supported by the Italian Foundation for Research on Cancer and by the Italian Ministry of Health, General Directorate of European and International Relations.
N. S. and J. R. H. were supported by grant number R44DK103377 from the United States National Institute of Diabetes and Digestive and Kidney Diseases.

J. R. H. Owns controlling interest in Connecting Health Innovations LLC (CHI), a company planning to license the right to his invention of the dietary inflammatory index from the University of South Carolina in order to develop computer and smart phone applications for patient counselling and dietary intervention in clinical settings. N. S. is an employee of CHI. The subject matter of this paper has not had any direct bearing on that work, nor has that activity exerted any direct influence on this project.

The authors' contributions were as follows: A.Z., M.M., C.L.V. and D.S. designed and conducted the case-control study, M.R. created the dataset for analyses, N.S. calculated DII and conducted all analyses and wrote the first draft of the manuscript, J.R.H., C.L.V., M.M., C.L.V., A.Z. and M.R. provided suggestions and revised the manuscript. All authors approved the final version of the manuscript.

There are no conflicts of interest.

\section{References}

1. Ferlay JSI, Ervik M, Dikshit R, et al. (2012) Cancer Incidence and Mortality Worldwide: IARC Cancer Base, no. 11. Lyon: International Agency for Research on Cancer.

2. Purdie DM \& Green AC (2001) Epidemiology of endometrial cancer. Best Pract Res Clin Obstet Gynaecol 15, 341-354.

3. Wynder EL, Escher GC \& Mantel N (1966) An epidemiological investigation of cancer of the endometrium. Cancer 19 , 489-520.

4. Keum N, Greenwood DC, Lee DH, et al. (2015) Adult weight gain and adiposity-related cancers: a dose-response metaanalysis of prospective observational studies. I Natl Cancer Inst 107, djv088.

5. Keibel A, Singh V \& Sharma MC (2009) Inflammation, microenvironment, and the immune system in cancer progression. Curr Pharm Des 15, 1949-1955.

6. Pan MH, Lai CS, Dushenkov S, et al. (2009) Modulation of inflammatory genes by natural dietary bioactive compounds. J Agric Food Chem 57, 4467-4477.

7. Thun MJ, Henley SJ \& Gansler T (2004) Inflammation and cancer: an epidemiological perspective. Novartis Found Symp 256, 6-21; discussion 22-28, 49-52, 266-269.

8. Warnberg J, Gomez-Martinez S, Romeo J, et al. (2009) Nutrition, inflammation, and cognitive function. Ann N Y Acad Sci 1153, 164-175.

9. de Mello VD, Schwab U, Kolehmainen M, et al. (2011) A diet high in fatty fish, bilberries and wholegrain products improves markers of endothelial function and inflammation in individuals with impaired glucose metabolism in a randomised controlled trial: the Sysdimet study. Diabetologia $\mathbf{5 4}$, $2755-2767$.

10. Khoo J, Piantadosi C, Duncan R, et al. (2011) Comparing effects of a low-energy diet and a high-protein low-fat diet on sexual and endothelial function, urinary tract symptoms, and inflammation in obese diabetic men. J Sex Med $\mathbf{8}$, $2868-2875$.

11. Luciano M, Mottus R, Starr JM, et al. (2012) Depressive symptoms and diet: their effects on prospective inflammation levels in the elderly. Brain Behav Immun 26, 717-720. 
12. Coussens LM \& Werb Z (2002) Inflammation and cancer. Nature 420, 860-867.

13. Cust AE, Allen NE, Rinaldi S, et al. (2007) Serum levels of C-peptide, IGFBP-1 and IGFBP-2 and endometrial cancer risk; results from the European prospective investigation into cancer and nutrition. Int J Cancer 120, 2656-2664.

14. Dossus L, Rinaldi S, Becker S, et al. (2010) Obesity, inflammatory markers, and endometrial cancer risk: a prospective case-control study. Endocr Relat Cancer 17, 1007-1019.

15. Friedenreich CM, Langley AR, Speidel TP, et al. (2013) Casecontrol study of inflammatory markers and the risk of endometrial cancer. Eur I Cancer Prev 22, 374-379.

16. Shivappa N, Steck SE, Hurley TG, et al. (2014) Designing and developing a literature-derived, population-based dietary inflammatory index. Public Health Nutr 17, 1689-1696.

17. Shivappa N, Steck SE, Hurley TG, et al. (2014) A populationbased dietary inflammatory index predicts levels of C-reactive protein in the Seasonal Variation of Blood Cholesterol Study (SEASONS). Public Health Nutr 17, 1825-1833.

18. Wirth MD, Burch J, Shivappa N, et al. (2014) Association of a dietary inflammatory index with inflammatory indices and metabolic syndrome among police officers. I Occup Environ Med 56, 986-989.

19. Shivappa N, Hebert JR, Rietzschel ER, et al. (2015) Associations between dietary inflammatory index and inflammatory markers in the Asklepios Study. Br J Nutr 113, 665-671.

20. Wood LG, Shivappa N, Berthon BS, et al. (2015) Dietary inflammatory index is related to asthma risk, lung function and systemic inflammation in asthma. Clin Exp Allergy 45, $177-183$.

21. Ruiz-Canela M, Zazpe I, Shivappa N, et al. (2015) Dietary inflammatory index and anthropometric measures of obesity in a population sample at high cardiovascular risk from the PREDIMED (PREvención con DIeta MEDiterránea) trial. $\mathrm{Br} J$ Nutr 113, 984-995.

22. Alkerwi A, Shivappa N, Crichton G, et al. (2014) No significant independent relationships with cardiometabolic biomarkers were detected in the observation of cardiovascular risk factors in Luxembourg study population. Nutr Res 34, 1058-1065.

23. Wood L, Shivappa N, Berthon BS, et al. (2015) Dietary inflammatory index is related to asthma risk, lung function and systemic inflammation in asthma. Clin Exp Allergy 45, 177-183.

24. Shivappa N, Hebert JR, Karamati M, et al. (2015) Increased inflammatory potential of diet is associated with bone mineral density among postmenopausal women in Iran. Eur J Nutr (Epublication ahead of print version 17 March 2015)

25. Zamora-Ros R, Shivappa N, Steck SE, et al. (2015) Dietary inflammatory index and inflammatory gene interactions in relation to colorectal cancer risk in the Bellvitge colorectal cancer case-control study. Genes Nutr 10, 447.

26. Shivappa N, Zucchetto A, Montella M, et al. (2015) Inflammatory potential of diet and risk of colorectal cancer in a case-control study from Italy. Br J Nutr 114, 152-158.

27. Shivappa N, Prizment AE, Blair CK, et al. (2014) Dietary inflammatory index and risk of colorectal cancer in the Iowa Women's Health Study. Cancer Epidemiol Biomarkers Prev 23, 2383-2392

28. Tabung FK, Steck SE, Ma Y, et al. (2015) The association between dietary inflammatory index and risk of colorectal cancer among postmenopausal women: results from the Women's Health Initiative. Cancer Causes Control 26, 399-408.

29. Wirth MD, Shivappa N, Steck SE, et al. (2015) The dietary inflammatory index is associated with colorectal cancer in the National Institutes of Health-American Association of Retired Persons Diet and Health Study. Br J Nutr 113, 1819-1827.
30. Shivappa N, Bosetti C, Zucchetto A, et al. (2015) Association between dietary inflammatory index and prostate cancer among Italian men. Br J Nutr 113, 278-283.

31. Shivappa N, Bosetti C, Zucchetto A, et al. (2015) Dietary inflammatory index and risk of pancreatic cancer in an Italian case-control study. Br J Nutr 113, 292-298.

32. Bravi F, Scotti L, Bosetti C, et al. (2009) Food groups and endometrial cancer risk: a case-control study from Italy. $A m J$ Obstet Gynecol 200, 293 e1-e7.

33. Franceschi S, Negri E, Salvini S, et al. (1993) Reproducibility of an Italian food frequency questionnaire for cancer studies: results for specific food items. Eur J Cancer 29A, 2298-2305.

34. Franceschi S, Barbone F, Negri E, et al. (1995) Reproducibility of an Italian food frequency questionnaire for cancer studies. Results for specific nutrients. Ann Epidemiol 5, 69-75.

35. Decarli A, Franceschi S, Ferraroni M, et al. (1996) Validation of a food-frequency questionnaire to assess dietary intakes in cancer studies in Italy. Results for specific nutrients. Ann Epidemiol 6, 110-118.

36. Willett W \& Stampfer MJ (1986) Total energy intake: implications for epidemiologic analyses. Am J Epidemiol 124, 17-27.

37. Rossi M, Edefonti V, Parpinel M, et al. (2013) Proanthocyanidins and other flavonoids in relation to endometrial cancer risk: a case-control study in Italy. Br J Cancer 109, 1914-1920.

38. La Vecchia C, Decarli A, Fasoli M, et al. (1986) Nutrition and diet in the etiology of endometrial cancer. Cancer 57, 1248-1253.

39. Levi F, Franceschi S, Negri E, et al. (1993) Dietary factors and the risk of endometrial cancer. Cancer 71, 3575-3581.

40. Negri E, La Vecchia C, Franceschi S, et al. (1996) Intake of selected micronutrients and the risk of endometrial carcinoma. Cancer 77, 917-923.

41. Pelucchi C, Dal Maso L, Montella M, et al. (2008) Dietary intake of carotenoids and retinol and endometrial cancer risk in an Italian case-control study. Cancer Causes Control 19, 1209-1215.

42. Filomeno M, Bosetti C, Bidoli E, et al. (2015) Mediterranean diet and risk of endometrial cancer: a pooled analysis of three Italian case-control studies. Br J Cancer 112, 1816-1821.

43. Galeone C, Augustin LS, Filomeno M, et al. (2013) Dietary glycemic index, glycemic load, and the risk of endometrial cancer: a case-control study and meta-analysis. Eur J Cancer Prev 22, 38-45.

44. Bravi F, Bertuccio P, Turati F, et al. (2015) Nutrient-based dietary patterns and endometrial cancer risk: an Italian case-control study. Cancer Epidemiol 39, 66-72.

45. Rossi M, Negri E, Bosetti C, et al. (2008) Mediterranean diet in relation to body mass index and waist-to-hip ratio. Public Health Nutr 11, 214-217.

46. Nagle CM, Olsen CM, Ibiebele TI, et al. (2013) Glycemic index, glycemic load and endometrial cancer risk: results from the Australian National Endometrial Cancer study and an updated systematic review and meta-analysis. Eur J Nutr $\mathbf{5 2}$, $705-715$.

47. Turati F, Galeone C, Gandini S, et al. (2015) High glycemic index and glycemic load are associated with moderately increased cancer risk. Mol Nutr Food Res 59, 1384-1394.

48. Bandera EV, Kushi LH, Moore DF, et al. (2007) Consumption of animal foods and endometrial cancer risk: a systematic literature review and meta-analysis. Cancer Causes Control 18, 967-988.

49. Gunter MJ, Schaub JA, Xue X, et al. (2012) A prospective investigation of coffee drinking and endometrial cancer incidence. Int J Cancer 131, E530-E536.

50. Hashibe M, Galeone C, Buys SS, et al. (2015) Coffee, tea, caffeine intake, and the risk of cancer in the PLCO cohort. Br J Cancer 113, 809-816. 
51. Gallicchio L, Matanoski G, Tao XG, et al. (2006) Adulthood consumption of preserved and nonpreserved vegetables and the risk of nasopharyngeal carcinoma: a systematic review. Int J Cancer 119, 1125-1135.

52. World Cancer Research Fund/American Institute for Cancer Research (2013) Continuous update project report. Food, nutrition, physical activity, and the prevention of endometrial cancer. http://www.dietandcancerreport.org

53. Steck S, Shivappa N, Tabung FK, et al. (2014) The dietary inflammatory index: a new tool for assessing diet quality based on inflammatory potential. Digest 49, 1-9.

54. Wang T, Rohan TE, Gunter MJ, et al. (2011) A prospective study of inflammation markers and endometrial cancer risk in postmenopausal hormone nonusers. Cancer Epidemiol Biomarkers Prev 20, 971-977.

55. Esmaillzadeh A, Kimiagar M, Mehrabi Y, et al. (2007) Dietary patterns and markers of systemic inflammation among Iranian women. J Nutr 137, 992-998.
56. Festa A, D'Agostino R, Howard G, et al. (2000) Chronic subclinical inflammation as part of the insulin resistance syndrome: the Insulin Resistance Atherosclerosis Study (IRAS). Circulation 102, 42-47.

57. Kaaks R, Lukanova A \& Kurzer MS (2002) Obesity, endogenous hormones, and endometrial cancer risk: a synthetic review. Cancer Epidemiol Biomarkers Prev 11, 1531-1543.

58. La Vecchia C, Franceschi S, Decarli A, et al. (1984) Risk-factors for endometrial cancer at different ages. J Natl Cancer Inst $\mathbf{7 3}$, 667-671.

59. Breslow NE \& Day NE (1980) Statistical methods in cancer research - the analysis of case-control studies. Statistical Methods in Cancer Research - The Analysis of Case-control Studies. IARC Scientific Publications no. 32. Lyon: WHO/ IARC.

60. D’Avanzo B, La Vecchia C, Katsouyanni K, et al. (1997) An assessment, and reproducibility of food frequency data provided by hospital controls. Eur J Cancer Prev 6, 288-293. 